\title{
A PRESENÇA DA EDUCAÇÃO FÍSICA NA ESCOLA DE APERFEIÇOAMENTO: ESTRATÉGIA PARA FORMAR O ESPECIALISTA (BELO HORIZONTE, 1927-1945)
}

\author{
THE PRESENCE OF PHYSICAL EDUCATION IN TRAINING AND DEVELOPMENT
} SCHOOL: A STRATEGY TO TRAIN SPECIALISTS (BELO HORIZONTE, 1927-1945)

\author{
LA PRESENCIA DE LA EDUCACIONN FISICA EN LA ESCUELA DE \\ PERFECCIONAMIENTO: UNA ESTRATEGIA PARA LA FORMACIÓN DEL \\ EXPERTO (BELO HORIZONTE, 1927-1945)
}

Ramona Morais*, Andrea Moreno**

Palavras-chave: História.

Docentes.

Educação Física. Especialização.
Resumo: Este artigo trata da disciplina Educação Física na Escola de Aperfeiçoamento de Belo Horizonte. Como marco inicial estabeleceu-se o ano de 1927, momento em que foi realizada a Reforma do Ensino de Minas Gerais, que previa a instalação da instituição, e como marco final o ano de 1945, seu último ano de funcionamento. Como hipótese se apresenta a compreensão de que a Escola de Aperfeiçoamento cultivou a necessidade de especialização no campo educacional. No caso da Educação Física, consideramos que a experiência ali cultivada sonhou a formação de professores especialistas nessa matéria. Para entender a proposta de ensino dessa disciplina, foi fundamental perseguir as ações dos professores Renato Eloy de Andrade e Guiomar Meirelles Becker, além dos registros das ex-alunas Diumira Campos de Paiva e Alzira Farnezzi. As fontes mobilizadas constituíram-se, prioritariamente, de documentos oficiais do estado: legislação educacional, o jornal Minas Geraes e a Revista do Ensino.

\section{Keywords:}

History.

Faculty.

Physical Education.

Specialization.

\begin{abstract}
This study focuses on Physical Education at the Training and Development School of Belo Horizonte. It starts in 1927, when the Primary Education Reform was enforced in the State of Minas Gerais, having as one of its aims the establishment of that institution, and it ends in 1945 - the school's last year of operation. It presents the hypothesis that the Training and Development School cultivated the need for specialization in education. In Physical Education, that experience dreamed of training teachers who specialized in that subject. In order to understand the teaching proposal for the discipline we examined the work of Renato Eloy de Andrade and Guiomar Meirelles Becker, who used to teach at the School, as well as former students Diumira Campos de Paiva and Alzira Farnezzi. The sources investigated included mainly State's official documents.
\end{abstract}

Palabras clave: Historia.

Docentes.

Educación Física.

Especialización.
Resumen: Este trabajo discute la Educación Física en la Escuela de Perfeccionamiento de Belo Horizonte. Como marco inicial se ha establecido el año 1927, cuando se llevó a cabo la reforma de la enseñanza en Minas Gerais Educación, que adelantaba la instalación de esa institución, y como marco final tomamos 1945, el último año en que funcionó. Como hipótesis, se presenta el entendimiento de que la Escuela de Perfeccionamiento cultivó la necesidad de especialización en el campo de la educación. En el caso de la Educación Física,consideramos que la experiencia allí cultivada soñó la formación de profesores especialistas en esa materia. Para comprender la propuesta de enseñanza de esa disciplina, fue fundamental buscar las acciones de los profesores Renato Eloy de Andrade y Guiomar Meirelles Becker, además de los registros de exalumnas Diumira Paiva Campos y Alzira Farnezzi. Las fuentes movilizadas fueron, en su mayoría, documentos oficiales del Estado: legislación educacional, el periódico Minas Gerais y la Revista do Ensino.
* Escola Municipal Anísio Teixeira. Belo Horizonte, MG, Brasil. E-mail: monitamorais@yahoo.com.br

** Universidade Federal de Minas Gerais. Belo Horizonte, MG, Brasil. E-mail: andreafaeufmg@gmail.com

Recebido em: 04-12-2015 Aprovado em: 14-06-2016 (c) (i) () Licence 


\section{INTRODUÇÃO}

Este estudo tematiza a Educação Física na formação de professores na Escola de Aperfeiçoamento em Belo Horizonte. O recorte temporal estabelecido tem como marco inicial o ano de 1927, momento em que foi realizada a Reforma do Ensino Primário em Minas Gerais, que teve como uma de suas diretrizes a instalação da Escola. A instituição, que passou a funcionar no ano de 1929, foi criada com o objetivo de aperfeiçoar, sob o ponto de vista da ciência, a formação dos professores primários no estado. Sua última turma diplomou-se em 1945, marco final do recorte temporal da pesquisa. Durante dezessete anos, a Escola de Aperfeiçoamento carregou o título de "Escola novidadeira", simbolicamente referindo-se à educação renovada. $\mathrm{Na}$ década de 1920, os ideais escolanovistas são disseminados como princípios na formação de professores, e essa instituição, fruto desse contexto, surge como promessa a efetivar o desejo de alinhar a formação docente aos pressupostos de uma pedagogia moderna. A Educação Física, disciplina que compôs o quadro de matérias nesse estabelecimento de ensino, também se vê imbuída desse ideal. Nesse movimento, interessou dar visibilidade à maneira como a Escola de Aperfeiçoamento cultivou a necessidade de especialização de professores dessa disciplina.

Como revelado em outros estudos que também investigaram a Escola de Aperfeiçoamento, há poucos registros sobre as experiências vivenciadas na instituição'. Por essa razão, várias frentes de trabalho foram levantadas para escrever essa história.

Os principais acervos pesquisados foram: Museu da Escola e a Biblioteca do Centro de Referência do Professor, a Biblioteca do Instituto de Educação de Minas Gerais, o Centro de Pesquisa, Memória e Documentação da Faculdade de Educação da UFMG, a Sala Helena Antipoff e o Setor de Obras Raras, ambos da Biblioteca Central da UFMG, o Centro de Memória da Educação Física, do Esporte e do Lazer da UFMG (CEMEF), a Imprensa Oficial, a Hemeroteca da Biblioteca Estadual Luis de Bessa, o Arquivo da Assembleia Legislativa de Minas Gerais e o Memorial Helena Antipoff ${ }^{2}$.

Neste garimpo, um vasto conjunto material foi mobilizado como fonte para a construção da narrativa.

\section{CAMINHO TRAÇADO}

A narrativa foi estruturada a partir da noção de jogos de escala, de Jacques Revel (1998). A variação de escala proposta pelo historiador é fruto de um contexto que buscou questionar os estudos históricos com enfoque macroanalítico. Contar uma história a partir de experiências singulares ajuda-nos a perceber melhor o embaralhamento das lógicas sociais. Optar por uma escala particular de observação produz efeitos de conhecimento, e ela pode ser posta a serviço de estratégias de construção do conhecimento. A escolha do individual não é vista como contraditória à do social: ela deve tornar possível uma abordagem diferente, ao acompanhar o fio de um destino particular - de um homem, de um grupo de homens - e, com ele, a multiplicidade dos espaços e dos tempos, a meada das relações nas quais ele se inscreve (REVEL, 1998, p. 21).

\footnotetext{
1 Isso se deve, em parte, a um incêndio que aconteceu no ano de 1953, no Instituto de Educação de Minas Gerais (IEMG), em que a biblioteca e arquivos da Escola de Aperfeiçoamento, na ocasião já extinta, foram destruídos. 
Tendo como pressuposto o entendimento de que o contexto é imanente às práticas, e que faz parte delas, no presente estudo interessou-nos partir do contexto macro que possibilitou a instalação da Escola de Aperfeiçoamento, para, em seguida, investigar a instituição e, posteriormente, compreender a Educação Física nesse espaço.

\section{O MOVIMENTO ESCOLANOVISTA}

A princípio, buscamos compreender a complexidade do movimento da Escola Nova, contexto educacional que possibilitou a instalação da Escola de Aperfeiçoamento. Ao analisar as investigações referentes a essa instituição de ensino, percebemos a estreita relação que se estabeleceu entre o desejo das autoridades mineiras de edificar um espaço para a formação de professores e uma ambiência que favoreceu e permitiu a concretização desse ideal.

No Brasil, a década de 1920 é caracterizada por ser um período de profundas transformações sociais. Os processos de industrialização e urbanização impactaram profundamente a formação dos sujeitos. Naquele contexto, caberia à escola formar o "novo homem", anunciado pela República. Os debates em torno das ideias escolanovistas ajudaram a configurar a necessidade de se "renovar" a educação.

Nos discursos pronunciados na época, a preocupação do professor deixa de ser com os programas de ensino e passa a ser direcionada para sua ação sobre o aluno. Os princípios da Escola Nova, em alguns momentos designada como Escola Ativa, indicavam que nem todos os sujeitos aprendiam da mesma forma. Defendia-se uma compreensão mais ampliada sobre a aprendizagem, reconhecendo a individualidade e a necessidade de ofertar circunstâncias favoráveis ao desenvolvimento individual. Para além desses pressupostos, a educação social, a articulação entre o conteúdo do ensino e a vida do aluno, a relação entre experiência e aprendizagem, a moral no processo educativo e a formação de hábitos também caracterizam 0 ideal da escola renovada.

Nesse cenário, segundo Martha Carvalho (2000), na busca por moldar a escola a partir das novas teorias pedagógicas, diversos sistemas de ensino foram criados.

O método Decroly foi um deles e foi utilizado nas escolas primárias mineiras ${ }^{3}$. O método de projetos, criado por William Kilpatrick a partir das idéias de John Dewey, também aparece como indicação na diretriz das intervenções pedagógicas nos grupos escolares. Conforme Dewey, não havendo separação entre vida e educação, esta deve preparar para a vida, promovendo seu constante desenvolvimento. ${ }^{4}$

Naquele contexto, a Educação Física também foi impactada pelos conhecimentos científicos, marca da educação renovada. A organização do ensino baseada no interesse dos sujeitos, a relação das vivências escolares com as experiências sociais, a formação de um coletivo eficiente e a compreensão do processo educativo por meio dos campos da Psicologia e da Biologia aparecem como princípios na organização do ensino da disciplina. Nesse cenário de mudanças e inovações, uma formação diferenciada de professores de Educação Física se fazia necessária.

3 Ovídio Decroly (1871-1932) foi um pedagogo belga que instituiu o sistema de ensino baseado na elaboração dos centros de interesses no processo de ensino e aprendizagem. Os "centros de interesse" seriam uma espécie de ideias-força, em torno das quais convergem as necessidades fisiológicas, psicológicas e sociais do aluno.

4 John Dewey (1859-1952) e William Kilpatrick (1871-1965) foram referências do movimento escolanovista em território norte-americano. 


\section{A REFORMA EM TERRAS MINEIRAS}

O estudo sobre a Reforma do Ensino em Minas Gerais de 1927, também denominada Reforma Francisco Campos, foi o segundo movimento realizado no trabalho. A referida reforma materializou, na dimensão prescritiva, o ideário escolanovista na proposta de reorganização do ensino mineiro. Nesse cenário, a Escola de Aperfeiçoamento é anunciada como instituição responsável por garantir a almejada reformulação da educação, ao surgir como promessa de novos rumos ao ensino primário no estado. No sétimo artigo da Lei ํㅜ 1036, de 25 de setembro de 1928, é a primeira vez em que se menciona oficialmente a proposta de instalação da Escola.

Para dar conta do aprofundamento das questões relativas à Reforma, mobilizamos como fontes o jornal Minas Geraes e a Revista do Ensino, impressos que fizeram a cobertura do I Congresso de Instrução Primária. Esse evento, realizado em maio de 1927, foi organizado pelo Secretário do Interior, Francisco da Silva Campos, no governo do Presidente do Estado de Minas, Antônio Carlos Ribeiro de Andrada. Tal encontro contou com a participação de professores e as teses debatidas serviram de embasamento para a organização da Reforma do Ensino, que foi realizada em outubro do mesmo ano.

Para o presente estudo, interessou-nos direcionar o olhar para os trabalhos que trataram dos assuntos referentes à formação do professor e às questões da Educação Física. A Comissão que tratava dos assuntos relativos a essa matéria era vinculada às questões de Higiene. No dia 12 de maio de 1927, oito teses foram debatidas pela Comissão de Higiene e Educação Física. Importa destacar, no detalhamento das conclusões apresentadas por Antonio Pereira da Silva, um dos membros da Comissão, a indicação de tempos, espaços, condições climáticas e o aporte da ciência como saberes que a Educação Física deveria portar. Tais prescrições revelam traços de um processo de constituição de uma disciplina com determinada especificidade. As conclusões anunciadas por Antônio Pereira foram as seguintes:

$1^{0}$ - A educação physica deve ser parte integrante do programma das escolas publicas primarias.

$2^{\circ}$ - Os exercícios, que serão educativos, utilitários e jogos, serão feitos de accordo:

a) com a edade do executante;

b) com a constituição, ou estado de saúde;

c) com o seu grau de entrenamento;

d) com o grau de difficuldade com que faz os exercícios anteriores;

e) com o resultado pratico, que se deseja obter;

f) com os pontos fracos que se deseja sejam fortificados ou aperfeiçoados;

g) com as condições climáticas;

h) com as circumstancias atmosphericas do momento;

i) com o terreno, ou material, que se possue.

$3^{\circ}$ - Organização de um campo e galpão próprio para exercícios.

4 - Apparelhamento para exercícios educativos - Manual de Bauman, viga horizontal, banco gymnastico e escada orthopedica.

5 - Anthropometria escolar - Collaboração medico-pedagogica.

6 - 0 ensino será, nos grupos e jardins de infância, ministrado por professoras especialistas, e, em escolas isoladas, pela professora, que fará apprendizagem nos grupos. 
7ํ. - Haverá nas Escolas Normaes um curso de especialização de "Educação Physica". Actualmente, porém, deverá ser constituída uma comissão que, sujeita a um critério único, dirija a "Educação Physica".

$8^{\text {- }}$ - No programma será incluída a gymnastica rythmica, excluindo-se os bailados e dansas clássicas. ${ }^{5}$

Destacamos os anúncios da 6 $6^{\underline{a}}$ e $7^{\underline{a}}$ teses que reforçam a necessidade da formação do especialista para o ensino da Educação Física nos jardins de infância e nos grupos escolares em Minas Gerais.

A reforma do estado atingiu o ensino primário e normal. A opção pelo primeiro nível de ensino se justificou pela posição estratégica ocupada pela escola primária em seu governo, que desejava constituir uma sociedade democrática, em que o direito ao voto deveria ser ampliado a todos os cidadãos. Naquele contexto, o voto era concedido apenas ao indivíduo escolarizado e, para se escolarizar o povo, a oferta do ensino primário deveria ser aumentada. As preocupações em relação ao ensino normal se devem ao fato de se considerar o trabalho do professor o alicerce sobre o qual se assenta a educação primária, sendo então 0 principal responsável por seu êxito ou fracasso. Reformar o ensino primário por meio de uma reformulação na formação dos professores possibilitou pensar-se em uma instituição de ensino voltada para o aperfeiçoamento da atuação docente. A criação da Escola de Aperfeiçoamento se coloca como estratégia promissora para a formação dos recursos humanos que auxiliariam na implantação da Reforma.

\section{LÓCUS DA MUDANÇA: A ESCOLA DE APERFEIÇOAMENTO}

A Escola de Aperfeiçoamento representou a materialização física das novas propostas para o ensino público em Minas Gerais. Sua finalidade era aperfeiçoar a formação de professores para a atuação no ensino primário nos moldes dos ideais da Escola Nova.

Tal instituição foi instalada oficialmente em 14 de março de 1929 e a primeira turma iniciou suas aulas em 19 de março do mesmo ano. A seguir, imagens da fachada do primeiro prédio da Escola de Aperfeiçoamento (Ilustração 1) e de algumas instalações da instituição (llustrações 2 e 3).

llustração 1 - Escola Maternal Melo Viana/ Escola de Aperfeiçoamento década de 1930

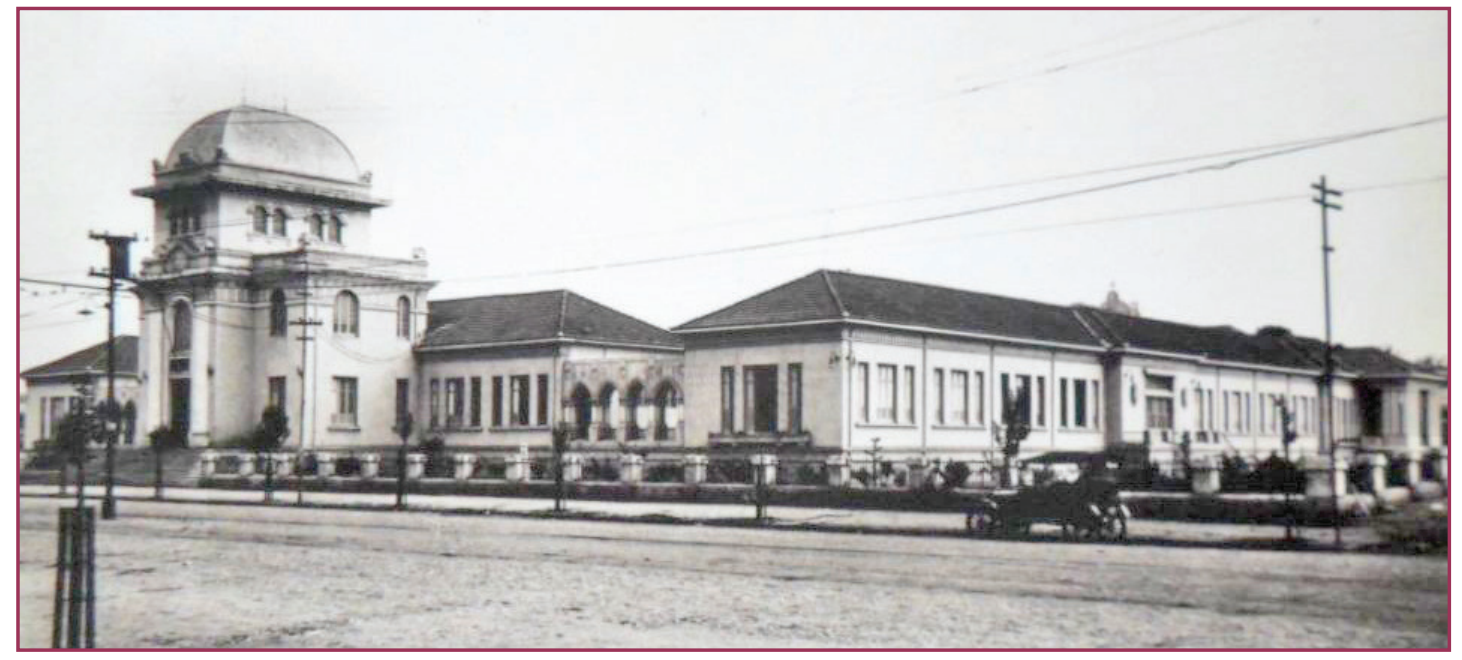

Fonte: Museu da Escola: 00175/99 Prédios Escolares.

$\overline{5 \text { Minas Geraes, p.7, } 13}$ de maio de 1927. 
llustração 2 - Escola de Aperfeiçoamento - vista do jardim década de 1930

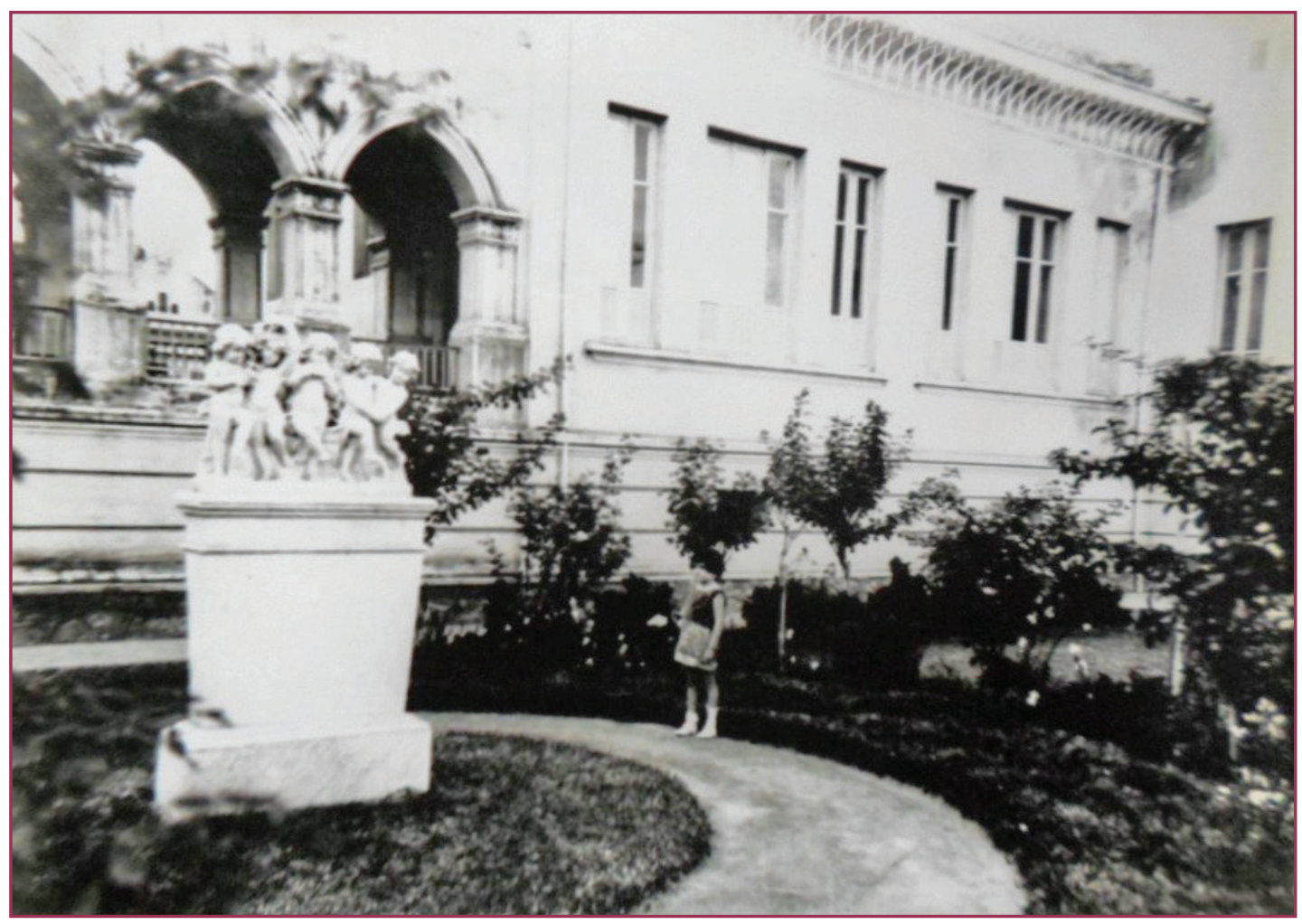

Fonte: Museu da Escola-00177/99 Prédios Escolares.

Ilustração 3 - Escola de Aperfeiçoamento - década de 1930

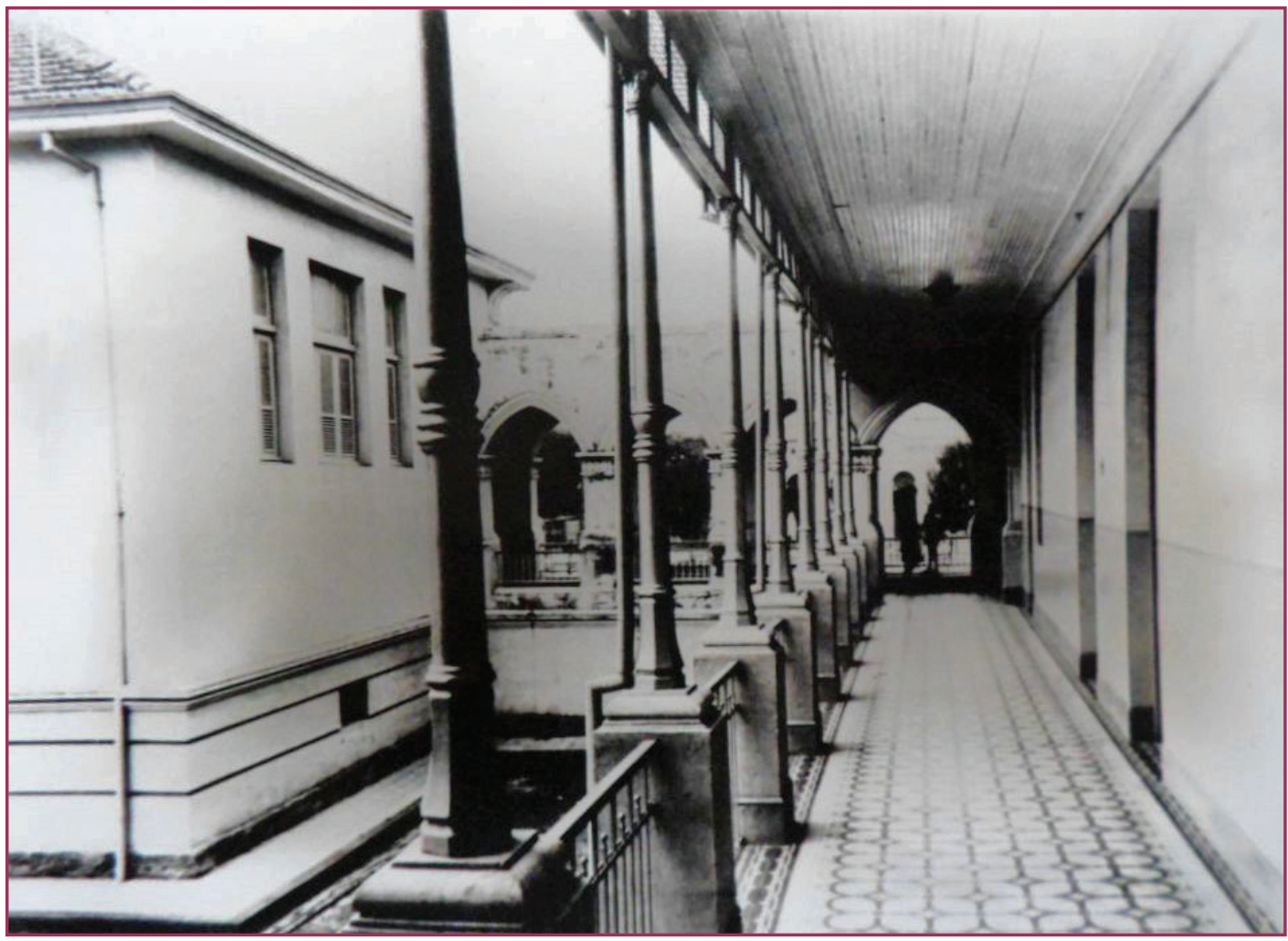

Fonte: Museu da Escola-00179/99 Prédios Escolares.

Conforme o regulamento da Escola de 1930, o curso oferecido tinha duração de dois anos e era dividido em dois períodos. No primeiro período, as matérias ensinadas eram: Biologia, Psychologia Educacional, Methodologia Geral, Methodologia de Lingua Patria, Socialização, 
Sociologia applicada á educação, Desenho e modelagem, Educação Physica e Organização de biblioteca. No segundo período fazia parte da grade de horários as matérias de Psychologia educacional, Methodologia particular a cada matéria do curso primario, Methodologia de Lingua Patria, Socialização, Estudo dos diversos systemas escolares, Educação Physica, Desenho e modelagem, Legislação escolar, Hygiene escolar.

As matérias do curso indicam as tendências do campo educacional do período. A presença da Biologia e da Psicologia deixam revelar os campos de conhecimento que naquele momento gozavam de legitimidade. 0 aprofundamento nas dimensões do funcionamento do organismo infantil, sob o viés psicológico e fisiológico, era compreendido como mecanismo a garantir melhores condições de aprendizado pelos sujeitos. Além disso, percebemos que 0 modo de fazer de cada matéria, representado pela Metodologia, é marca de um contexto que valorizou o método no processo educacional. Como a indicação é de que cada saber possuía um modo de fazer, indícios de uma especialização em cada matéria já começavam a aparecer. A Socialização também ocupa lugar de destaque, tendo em vista a concepção de que a escola passa a ser compreendida como sociedade em miniatura.

Possuir diploma da Escola de Aperfeiçoamento passou a ser condição essencial para a ocupação dos melhores cargos na área educacional. Além da determinação do regulamento, o texto do diploma de conclusão do curso também indica o privilégio de que as professoras alunas gozariam ao término dos dois períodos da Escola. A llustração 4 detalha os termos de um diploma de 1932.

llustração 4 - Diploma da Escola de Aperfeiçoamento da professora Imene Guimarães

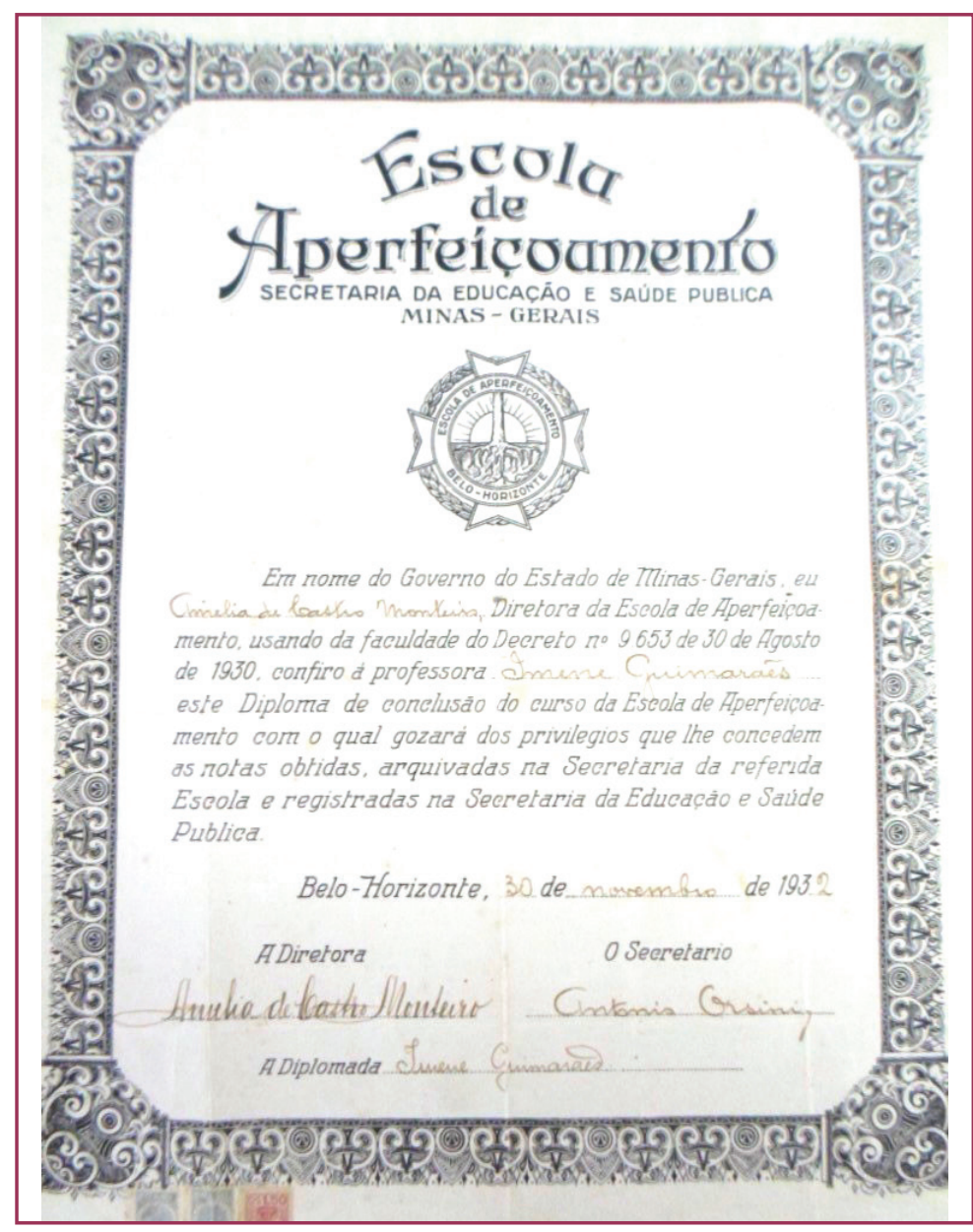

Fonte: Museu da Escola do Centro de Referência do Professor. 
O regulamento ainda determinava que a prática profissional deveria ser realizada nas classes anexas. Essa exigência possivelmente esteve ligada à compreensão de que por meio dos novos métodos apreendidos durante o curso, novas intervenções em sala de aula passariam a integrar o fazer docente.

Lúcio José dos Santos foi escolhido para assumir a direção da escola, tendo ocupado o cargo por um ano e sido substituído por Amélia de Castro Monteiro, que permaneceu no cargo até o fim da instituição. Os dois pertenciam ao meio religioso e suas indicações se apresentaram como uma estratégia do governo, para manter a Igreja como aliada em sua plataforma política. Tendo em vista o avanço dos ideais liberais no campo da educação, a presença de um representante católico nessa instituição de ensino amenizaria a oposição entre as duas vertentes da educação: liberal e católica.

O corpo docente da Escola de Aperfeiçoamento se formou pela junção de dois diferentes grupos. Um deles era formado por professoras mineiras que estudaram nos Estados Unidos. Alda Lodi, Lúcia Schmidt Monteiro de Castro (mais tarde Lúcia Casasanta) ${ }^{6}$ e Amélia de Castro Monteiro realizaram intercâmbio na Universidade de Colúmbia, berço da metodologia e difusão dos pensamentos da Escola Ativa, e estiveram na Escola durante todo o período de existência. O outro grupo foi formado com a chegada da Comissão Pedagógica Europeia: Theodore Simon, de Psicologia, lecionou de fevereiro a maio de 1929; Leon Walter, também de Psicologia, permaneceu na Escola durante o primeiro semestre de 1929; Mme. Artus Perrelet, de Desenho e Modelagem, trabalhou na instituição por dois anos; Helena Antipoff, Psicologia, e Jeanne Louise Milde, Desenho e Modelagem, estiveram presentes durante todo o período de existência da Escola e anos mais tarde se naturalizam brasileiras ${ }^{7}$. Complementando 0 corpo docente, Renato Eloy de Andrade, outro brasileiro que também esteve no exterior, era responsável pela cadeira de Educação Físicå. O professor faleceu em 1939, vítima de tuberculose, e foi substituído por sua assistente, Guiomar Meirelles Becker, que lecionou na Escola até o seu término.

Percebendo a presença da Educação Física nos dois anos da grade de matérias da Escola, uma questão central é colocada: qual era o lugar dessa disciplina na qualificação do professorado mineiro?

Uma resposta possível para essa indagação está na análise de um dos itens do Regulamento da Escola, intitulado Curso de Especialização. $020^{\circ}$ artigo detalha que as professoras alunas da Escola de Aperfeiçoamento que mostrassem vocação em algumas matérias seriam orientadas a se especializarem nas referidas áreas. 0 documento esclarece ainda que serviriam de critério para a admissão nos cursos de especialização as notas alcançadas nos dois anos da instituição, além de provas aplicadas pelo corpo docente. Com esse dado, a presença da Educação Física nesse estabelecimento se apresentava como

6 A mudança do nome aconteceu em virtude do casamento com Mário Casasanta, Inspetor Geral da Instrução Pública no governo de Antônio Carlos Ribeiro de Andrada.

7 Prates (1989) assim caracteriza os professores europeus: Theodore Simon, médico francês, envolvido com a disciplina de Psicologia Experimental; Leon Walter, também médico, trabalhou com Claparède em Genebra e buscou compreender as necessidades das crianças nos estudos de Psicologia Funcional; Mme. Artus Perrelet, professora de Artes Plásticas (Desenho e Modelagem) que esteve na Escola por dois anos; Jeanne Louise Milde, escultora belga e professora da Academia de Belas Artes de Bruxelas; Omer Buyse, professor belga que foi diretor do ensino técnico em seu país; Mme. Hélène Antipoff, professora russa contratada pelo governo mineiro para dar continuidade aos trabalhos de Psicologia Experimental de Theodore Simon e Leon Walter. Mme. Hélène Antipoff foi docente do Instituto João Jacques Rousseau, assessora de Claparède, e aprofundou as investigações sobre a Psicologia na fundação do Instituto Pestallozzi (p. 99). 
importante na formação docente. Possivelmente, já se vislumbrava nesse cenário a constituição e consolidação de áreas do conhecimento que deveriam compor a educação primária, e a Educação Física se fazia presente.

\section{A EDUCAÇÃO FÍSICA NA ESCOLA DE APERFEIÇOAMENTO}

A partir dos pressupostos de uma educação renovada, como a Educação Física foi pensada, produzida e conduzida pelos sujeitos que dela se encarregaram nesse estabelecimento de ensino?

Ao buscar respostas para o questionamento anunciado, importa destacar que, naquele cenário, outras iniciativas conferiram centralidade à cultura física na formação dos sujeitos.

Uma das diretrizes da Reforma de Ensino de 1927 foi a criação da Inspetoria, órgão específico capaz de orientar e disseminar os discursos sobre o que e como fazer o ensino da Educação Física Escolar. Além disso, a oferta de cursos intensivos de Educação Física e a presença dessa disciplina na Escola de Aperfeiçoamento com a possibilidade de especialização na área demonstram que a educação do físico ganhou importância na proposta de uma educação renovada.

Três sujeitos nos ajudam a compreender fragmentos da história da Educação Física na Escola de Aperfeiçoamento: Renato Eloy de Andrade e Guiomar Meirelles Becker, enquanto docentes, e Diumira Campos de Paiva, ex-aluna do estabelecimento, diplomada em 1931.

A Escola de Aperfeiçoamento, como instituição modelar, deveria ter, no seu quadro de funcionários, docentes qualificados. No caso da Educação Física, Renato Eloy, o respeitado Inspetor, foi escolhido para assumir o cargo. Tal indicação se mostra como mais um indício do investimento realizado na organização do estabelecimento de ensino.

Um dos registros do trabalho desse docente foi a produção do artigo intitulado Educação Physica - uma das bases para methodologia, publicado no periódico da instituição denominado A Voz da Escola. Chama-nos atenção a referência dada no título do texto ao uso do termo methodologia, marca daquele contexto, o que parece revelar uma preocupação maior com 0 ensino, com o trato pedagógico da Educação Physica.

Guiomar Meirelles Becker foi a auxiliar de Renato em distintas frentes de ação envolvendo a Educação Física. Uma atuação que Ihe conferiu destaque foi a participação no Congresso de Instrução Primária de 1927, onde ela debateu sobre diversos assuntos referentes à prática de exercícios físicos nas escolas. A parceria estabelecida com o professor iniciou-se na Inspetoria e estendeu-se nas aulas ministradas na Escola de Aperfeiçoamento.

Convém ressaltar sua autoria no livro Educação Física Infantil, publicado em 1942. A obra foi fruto do trabalho desenvolvido durante três anos com os alunos do ensino primário das classes anexas da Escola de Aperfeiçoamento. Guiomar Meirelles, professora da instituição na ocasião, reuniu todos os registros realizados e publicou o que pode ser designado como manual para professores que atuavam com a Educação Infantil. O livro foi organizado utilizando como principal conteúdo a chamada "ginástica historiada". A llustração 5 traz o registro da capa do livro. 
Ilustração 5 - Capa do livro Educação Física Infantil - 1942

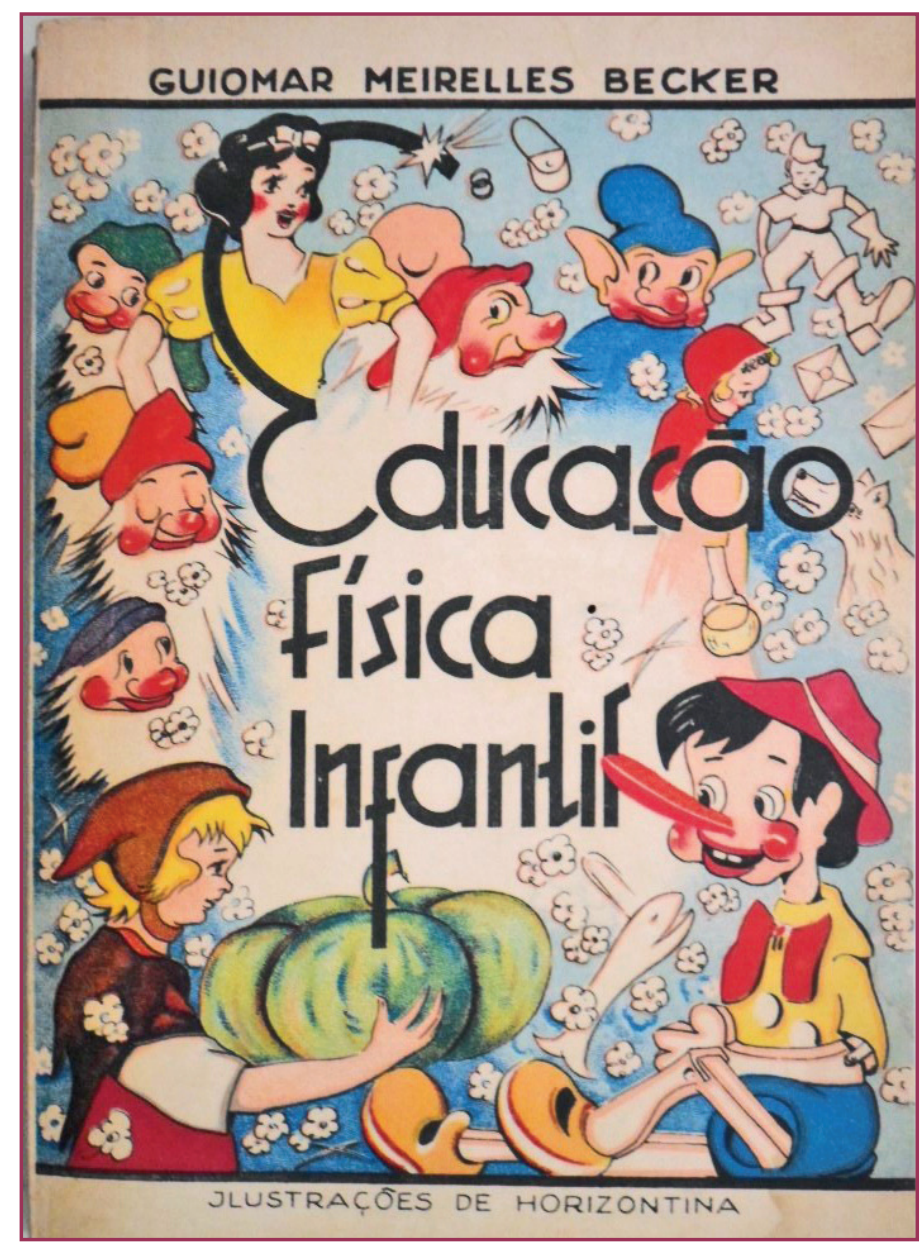

Fonte: Biblioteca do Centro de Referência do Professor - Acervo Alda Lodi.

A partir das atuações realizadas por Renato Eloy e Guiomar Meirelles, consideramos que ambos podem ser chamados de "mediadores culturais", na medida em que são compreendidos como pessoas que, sob circunstâncias variadas e interesses diversos, ajudaram a construir a Educação Física nessa instituição. Eles tiveram suas trajetórias biográficas relacionadas à formação de professores de Educação Física, bem como circularam por diversos espaços que tinham como finalidade cuidar da formação do especialista.

Partindo da noção de mediadores apresentada por Gruzinski (2001), também estão envolvidos nesse cenário os sujeitos que foram impactados pelas atuações dos professores; no caso, os alunos dessa Escola. Como eles se apropriaram dos conhecimentos sobre a Educação Física? Tal questionamento sugere a noção de apropriação anunciada por Chartier (1990).

Por meio da trajetória de Diumira Campos de Paiva, uma das alunas da Escola de Aperfeiçoamento que direcionou sua formação para a atuação com a Educação Física, temos indícios de como sua passagem pela instituição pode ter influenciado essa escolha.

Diumira fez parte da Inspetoria e no VII Congresso Nacional de Educação realizado em 1935 apresentou a tese "Educação Física na escola primária". Esse trabalho pode ser considerado uma síntese dos conhecimentos acessados durante sua permanência no curso da instituição.

Percebemos que a preocupação com a formação do especialista em Educação Física para atuar nas escolas mineiras se fazia presente. A organização de cursos intensivos a partir 
de 1928 foi uma das principais ações empreendidas nesse cenário. Importa destacar os cursos de 1933 e 1934. Ambos tiveram um caráter de maior sistematização e normatização e foram realizados na Escola de Aperfeiçoamento. 0 jornal Minas Geraes ainda confere prestígio à realização dos cursos, que foram assim descritos:

Os cursos intensivos de Educação Physica, destinados á formação rápida de professores especializados, têm funccionado na Escola de Aperfeiçoamento, sob a orientação directa e pessoal do professor Renato Eloy de Andrade, technico de reconhecido valor, que vem dando grande brilho e relevo á Inspectoria de Educação Physica em nosso Estado, departamento que dirige com rara proficiência. ${ }^{9}$

Essa fonte traz indícios de que na Escola de Aperfeiçoamento funcionaram os cursos intensivos destinados à formação especializada de professores de Educação Física. Podemos supor que os cursos intensivos, ao serem ministrados no mesmo espaço de formação do curso geral da Escola, apresentaram marcas da formação veiculada na própria instituição. A oferta dessa formação diferenciada na Educação Física nos permite dizer que a Escola de Aperfeiçoamento criou condições e incentivou a formação de docentes especialistas. Uma novidade dos cursos de 1933 e 1934 foi a entrega de certificados de especialização.

$\mathrm{Na}$ presente investigação, foi possível localizar o diploma de uma aluna do curso do ano de 1933, Alzira Farnezzi, conforme se observa na ilustração 6.

Ilustração 6 - Certificado de Alzira Farnezzi - Curso Intensivo de Educação Física em 1933.

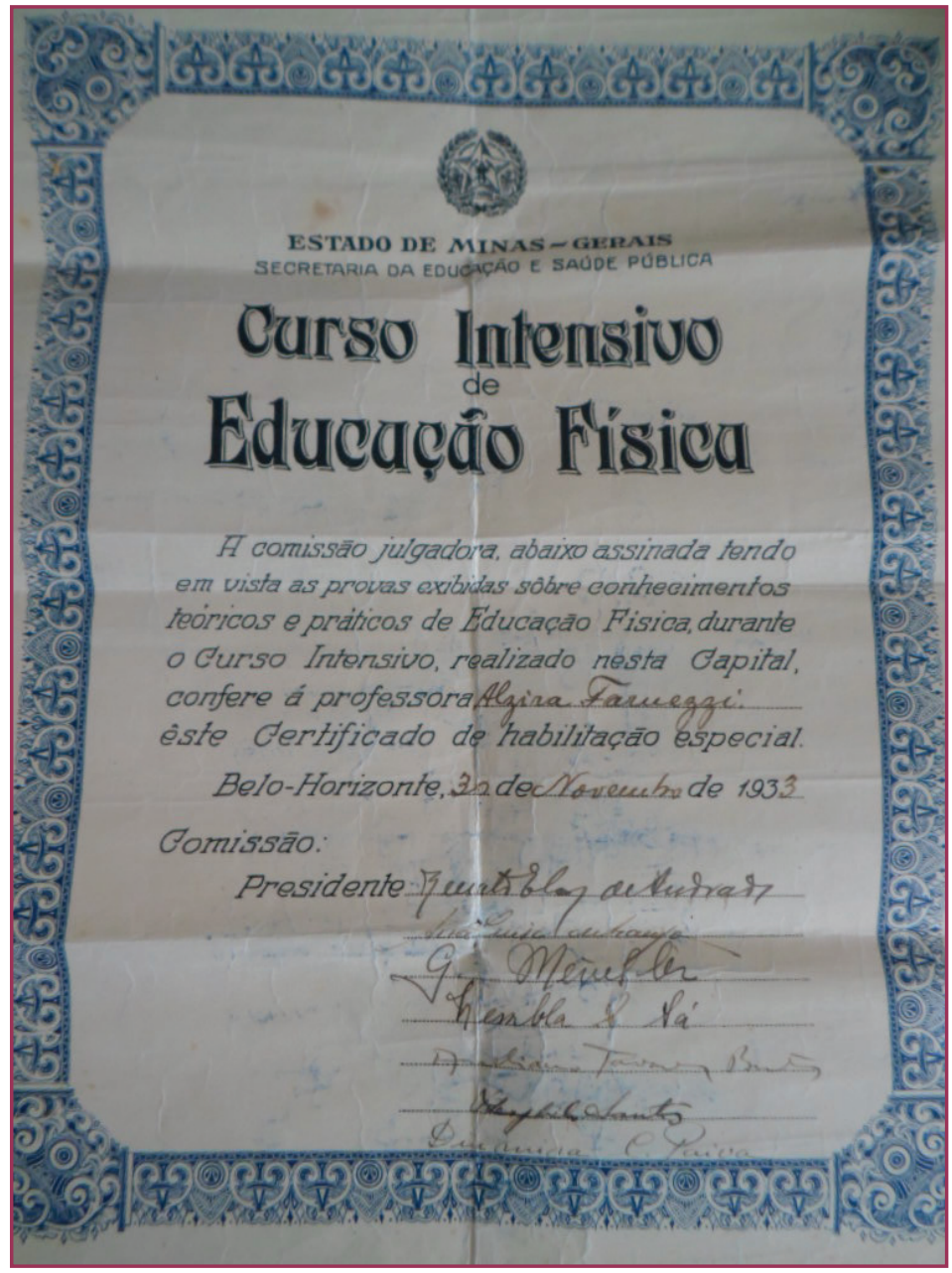

Fonte: Acervo pessoal da família Farnezzi. 
No CEMEF, foi localizado um caderno de Educação Física de Alzira Farnezzi, datado de 1935. Como as datas registradas no diploma e no caderno não coincidem, podemos supor que Alzira realizou outro curso intensivo em 1935, ou que ela foi aluna do curso da Escola de Aperfeiçoamento e talvez não tenha chegado a concluir os dois anos de trabalho na instituição, pois não encontramos seu nome nas listas de formandas da Escola publicadas no jornal Minas Geraes. Interessa-nos destacar o conteúdo do caderno, pois ele revela aquilo que foi ensinado, marca da prática em si. Suas páginas trazem registros sobre calistenia, ginástica de chão, jogos, planos de ginástica historiada, ginástica com bastões e exercícios respiratórios.

O programa de Educação Física da EA, datado de 1937, também nos oferece indícios da formação disseminada na instituição.

Ao analisar o conteúdo desse documento, percebemos um caráter dúbio em sua orientação. Na primeira fase, a disciplina destinava-se a garantir às professoras alunas uma formação físico-corporal, intelectual e teórica sobre a área. No segundo momento, buscava-se preparar as alunas para a docência na educação primária, ou para o trabalho de orientação de outros docentes. Prates (1989) revela que a Educação Física tinha como função garantir a formação integral do sujeito. Na prescrição do programa de Educação Física, percebemos a ideia de um "tripé" na preparação profissional. Os conteúdos são distribuídos em três grandes áreas: História, Organização do ensino e Biologia/Psicologia. Em relação à classificação das atividades, as ginásticas, os jogos, os clubes e as excursões são listados como colaboração com a cadeira de Socialização. Interessante notar a referência aos esportes. A natação também é prescrita, com exercícios aquáticos e técnicas de salvamento. Ao acessar imagens sobre a Escola, a foto de uma piscina pode revelar que tal prescrição se materializou no cotidiano da instituição, conforme se observa na llustração 7.

Ilustração 7 - Escola de Aperfeiçoamento - piscinas e banheiros da década de 1930-BH.

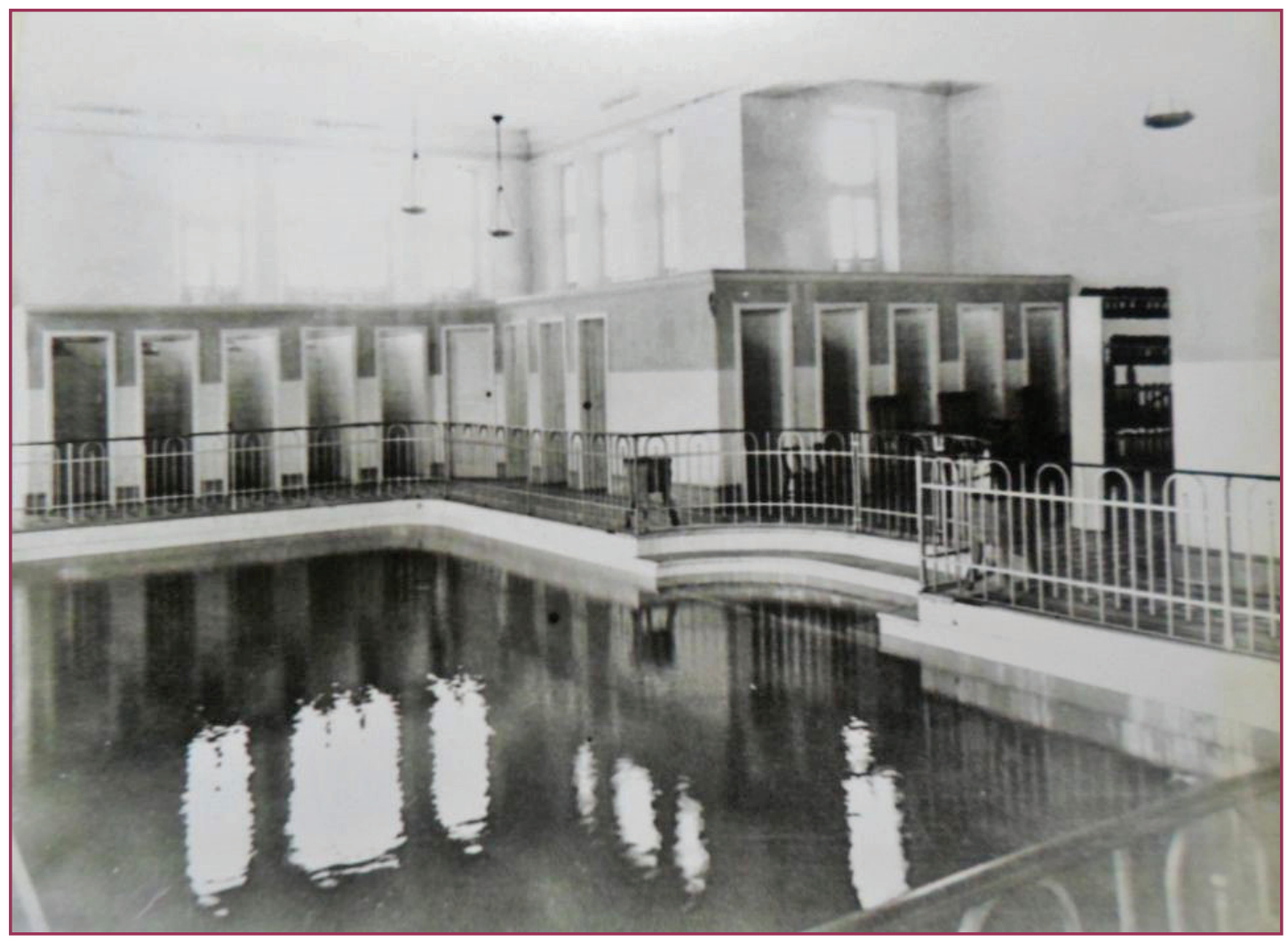

Fonte: Museu da Escola: 00178/99 Prédios Escolares. 


\section{CONSIDERAÇÕES FINAIS}

$\mathrm{Na}$ Escola de Aperfeiçoamento, o conhecimento sobre a infância, o interesse do aluno como eixo do trabalho pedagógico, os saberes da Psicologia e da Fisiologia embasando 0 exercício docente, os jogos e a calistenia como práticas prescritas para as aulas de Educação Física sinalizam para o desejo de uma especialização do professorado.

Vago (2010) elenca cinco estratégias de formação do professorado para o ensino da Educação Física a partir de 1925 em Minas Gerais. Segundo o autor, a circulação da Revista do Ensino; a realização do I Congresso de Instrução Primária; a Reforma do Ensino Normal e Primário do Estado; a criação da Inspetoria de Educação Física e a realização dos cursos intensivos foram iniciativas que se desdobraram na afirmação e consolidação da Educação Physica como disciplina escolar. Tais empreendimentos reconfiguraram o programa de ensino de tal disciplina nas escolas normais e no ensino primário, além de ter aberto possibilidades para uma crescente especialização docente que passou a ser exigida para o seu ensino nas escolas. Complementando o argumento anunciado por Vago, incluímos a formação oferecida pela Escola de Aperfeiçoamento como mais uma estratégia que ajudou a cultivar a necessidade de uma especialização docente para professores de Educação Física.

Cientes dos desdobramentos das iniciativas levadas a cabo nas décadas de 1920, 1930 e 1940 em Minas Gerais, ratificamos que as ações realizadas em torno da disciplina de Educação Física na Escola de Aperfeiçoamento ajudaram a construir o cenário de formação da professora de Educação Física nos anos posteriores. Os sujeitos que dela se encarregaram na instituição, os discursos veiculados sobre a cultura física, a organização de outros empreendimentos, como os cursos intensivos realizados a partir de 1947, no IEMG, bem como a criação das duas Escolas de Educação Física em Minas Gerais, fundadas em 1952, nos oferecem pistas de como foi possível pensar na especialização docente em Educação Física em Minas Gerais.

\section{REFERÊNCIAS}

CARVALHO, Marta Maria Chagas de. Modernidade Pedagógica e modelos de formação docente. São Paulo em Perspectiva, v. 14, n. 1, p. 111-120, jan./mar. 2000.

CHARTIER, Roger. A História Cultural: entre práticas e representações. Rio de Janeiro: Bertrand Brasil, 1990.

GRUZINSKI, Serge. O Pensamento Mestiço. São Paulo: Companhia das Letras, 2001.

PRATES, Maria Helena Oliveira. A introdução oficial do movimento de escola nova no ensino público de Minas Gerais: a Escola de Aperfeiçoamento. 1989. vi, 232 [101] f., enc. Dissertação (Mestrado em Educação) - Faculdade de Educação, Universidade Federal de Minas Gerais, Belo Horizonte, 1989.

REVEL, Jacques. (Org.). Jogos de Escalas, a experiência da microanálise. Rio de Janeiro: Fundação Getulio Vargas, 1988.

VAGO, Tarcísio Mauro. Histórias de Educação Física na Escola. Belo Horizonte: Mazza Edições, 2010. 
